\title{
REFORMA DO ESTADO E DO ENSINO SUPERIOR: FLEXIBILIZAÇÃO CURRICULAR E MUNDO DO TRABALHO
}

\author{
Sarita Medina da Silva* \\ Mário Borges Netto*

\begin{abstract}
Não se sabe se é cômico ou sinistro, por ocasião de uma perpétua, irremovível
e crescente penúria de empregos, impor a cada um dos milhões de desempregados - e isso a cada dia útil de cada semana, de cada mês, de cada ano - a procura "efetiva e permanente" deste trabalho que não existe
\end{abstract} \\ (FORRESTER, V.).
}

\begin{abstract}
RESUMO
Examina-se nesse artigo as tensões e contradições decorrentes da relação entre formação universitária e mercado procurando mostrar como as proposições das políticas de reformas educacionais têm se valido da noção de flexibilização curricular, pautando-se por suas matrizes orientadoras re-significadas e aplicadas ao campo educacional. Tomam-se como categoriaschaves inter-relacionadas: reestruturação produtiva; reforma do Estado; mercado de trabalho e formação acadêmica. Tal estudo reporta-se inicialmente à reestruturação produtiva e mercado de trabalho no contexto da globalização. $O$ foco é a reforma do ensino superior - com destaque para as diretrizes curriculares nacionais. Por fim, aborda a presença de um dilema entre flexibilização, mercado e autonomia como determinantes dos paradigmas

* Doutora em Educação (UNICAMP) e professora da Faculdade de Educação da UFU.

** Graduando do Curso de Pedagogia da Faculdade de Educação da UFU.
\end{abstract}


definidores dos perfis profissionais, ao serem tomados como referências para os projetos curriculares nas Instituições de Ensino Superior.

PALAVRAS-CHAVE: Reforma do Estado. Ensino superior. Formação universitária. Flexibilização. Mercado. Autonomia.

\begin{abstract}
This article examines the tensions and contradictions in the relationship between academic education and market. It tries to show how propositions of the education reform policies have relied on the notion of curricular flexibleness, whose matrixes - resignified and applied to the educational field - guide such policies. Productive re-structuring, State reform, job market, and academic education are, therefore, taken as interrelated key categories. First, this study focuses on the productive re-structuring and job market in the globalization context. Then its focus changes to the academic education reform, above all to the national curricular guidelines. At last, it approaches flexibleness, market, and autonomy as determining elements of the paradigms which define professional profiles since they taken as a reference to the curricular planning in academic education institutions.
\end{abstract}

KEYWORDS: State reform. Academic teaching. College education. Flexibleness. Market. Autonomy.

O objetivo deste texto é analisar o processo de flexibilização como um elemento determinante das reformas educativas, que vêm orientando os paradigmas definidores dos perfis profissionais nas Instituições de Ensino Superior - IES. Para tanto, tem-se como cenário as mudanças ocorridas no mundo do trabalho em decorrência da globalização da economia no tocante às transformações mundiais atuais e seus impactos nas práticas sociais e educacionais a partir dos anos de 1990.

Educ. e Filos., Uberlândia, v. 21, n. 42, p. 193-226, jul./dez. 2007. 
As políticas educacionais e as reformas delas decorrentes, efetivadas no ensino acadêmico brasileiro a partir da década de 1990, têm suscitado fervorosos debates como aqueles relativos ao modo de concepção e implementação de tais políticas e reformas, sobretudo quanto aos pressupostos e às finalidades que procuram contemplar. Ante as transformações em processo na sociedade brasileira, distintas vertentes teóricas procuram apreender o significado das reformas do sistema de ensino superior e dos novos papeis a serem assumidos pela educação. As reformas têm mostrado que seus propósitos procuram adequar o sistema educacional aos novos tempos, atribuindo à universidade nova função e novo significado no contexto do chamado processo de globalização.

Nossa perspectiva teórico-metodológica tem como referência as formulações de Popkewitz, sobre as reformas contemporâneas como manifestações de padrões históricos que possibilitam refletir sobre as mesmas, tendo-se em vista as intenções e práticas político-pedagógicas direcionadas a proposições e processos de mudanças que acompanham as inovações educacionais articuladas com as relações de poder e como parte do processo de regulação social que permite postular uma epistemologia das reformas na relação entre conhecimento, instituições e poder (1997, p. 39).

Para Claus Offe (1990), as políticas sociais também têm em sua base uma concepção teórica que reflete sempre o desenvolvimento histórico da estrutura social e econômica capitalista de tal forma que o Estado utiliza-se das políticas de estado de bem-estar como uma estratégia para garantir o equilíbrio e a lógica entre força de trabalho e setor produtivo.

Nesse contexto, verifica-se que as recomendações, diretrizes e metas das políticas de reformas em âmbito externo orientada pelos organismos internacionais, bem como outras medidas legais abriram caminho para a perspectiva modernizadora da universidade. Outros procedimentos como planos e projetos foram instituídos em âmbito nacional para dar encaminhamento à reforma do ensino pela implementação de novas diretrizes curriculares. 
A idéia de reforma hoje, na maioria das vezes, articula-se com a idéia de inovação e modernização, movida por imperativos operacionais coerentes com a racionalização e a eficiência econômica. Nesse sentido, impõe-se a importância e relevância de uma reflexão sobre as proposições que integram as propostas de reformas para o ensino superior, tendo em vista a relação entre modernização do Estado e transformação da universidade.

Dessa forma, as alterações no ensino acadêmico, assim como a reconfiguração da educação superior, integram o processo de regulamentação da Lei de Diretrizes e Bases da Educação Nacional/LDB (Lei $n^{\circ}$ 9.394/96). Essa lei prevê mudanças na organização, na estrutura e no funcionamento das universidades, que redefinem o papel do ensino universitário para suprir demandas do contexto de mudanças, sobretudo a produção do conhecimento e a formação profissional, e aponta como alternativa a diversificação e diferenciação institucional por meio da flexibilização. Para garantir o princípio da flexibilização como forma de romper com a rigidez dos "currículos mínimos", todos os cursos deveriam, a partir daí, ter suas diretrizes curriculares específicas reformuladas e aprovadas pelo Ministério da EducaçãoMEC e pelo Conselho Nacional da Educação-CNE.

Dourado (1999) considera que está se difundindo no país o ideário de um novo paradigma para o processo produtivo em escala mundial, no qual articulam-se a expansão da educação e do conhecimento por meio da reconceptualização e (re)valorização sob a ótica mercadológica que orienta a ordem econômica mundial. Isso "vem se expressando, através de palavras como: diversificação, diferenciação, flexibilidade, competitividade, modernização, desempenho, eficiência, integração, parceria, autonomia, adaptabilidade e qualidade" (1999, p.10). Significa dizer que há uma consonância entre as reformas em curso no país e as estratégias de legitimação de um projeto sócio-econômico predominante em nível mundial. Trata-se de um paradigma de implementação de políticas de reformas educacionais que integram a agenda assumida junto às potências econômicas que orientam o movimento reformista destinado especialmente para América Latina.

Educ. e Filos., Uberlândia, v. 21, n. 42, p. 193-226, jul./dez. 2007. 
Podemos considerar que o MEC/CNE e as instituições de ensino, na implementação de uma política de reforma curricular, recorre ao discurso político-cultural articulado com as necessidades de mudanças educacionais. E como atores intermediários diretos e indiretos de tais reformas, estão os professores e a sociedade, com suas práticas pedagógicas e, em última instância os alunos em seus processos de formação.

Nesse sentido, há um imperativo que vincula a flexibilização curricular e formação como centro do discurso oficial atual, pois as proposições oficiais possibilitam reconhecer na idéia de flexibilização o eixo integrador e articulador de um novo paradigma, uma nova configuração curricular, mediante os padrões político-culturais predominantes.

Partindo daí, podemos supor que a reformulação das IES e Instituições Federais de Ensino Superior-IFES expressam um modelo de formação que se confrontam com o movimento de mudanças sociais do país e com as contradições emergentes do entrecruzamento de bases das orientações com ações institucionais e perspectivas apontadas historicamente pelos movimentos da sociedade como um todo.

A problematização e a análise da flexibilização curricular como categoria central deste texto confrontada com as perspectivas expressas nas políticas de reformas e nos planos institucionais, constituem elemento fundamental e recorrente para a compreensão da reconfiguração do ensino superior. Como também pode revelar um indicativo de uma nova identidade para as IES e IFES no interior das políticas reformistas. Assim, supomos que, integrada às demais políticas educacionais reformistas, a reformulação curricular movida pelo imperativo da flexibilização expressa a clara opção por uma formação sintonizada com um novo paradigma profissional, que pode refletir um processo de perda de identidade e do papel social da universidade e do profissional que ela forma.

À luz destas e de outras referências, consideramos importante compreendermos o significado da reforma do ensino universitário a partir da segunda metade dos anos de 1990, com base em seus 
pressupostos, suas políticas e legislações, assim como seu significado histórico para o contexto político-social da educação brasileira.

\section{Reestruturação produtiva, mercado de trabalho e formação universitária}

O século XX, que iniciou como o século das massas, despedese como o século do desemprego em massa. As contradições geradas pelo sistema capitalista continuam se reproduzindo. Cresce a capacidade de produzir - fundamentada no avanço da tecnologia, telecomunicação e transporte -, mas aumenta a degradação do trabalho, exclusão social e a incerteza da própria sobrevivência do ser humano. O mundo do trabalho sofre e produz pressões sociais, econômicas, políticas, que interferem em toda a rede social. As alterações no mundo do trabalho produzem influências na vida do trabalhador, sobretudo, quanto a sua qualificação e educação profissional. As mudanças ocorridas no mundo, em função da globalização e da internacionalização da economia, têm influenciado as práticas sociais. "Esse processo tem tido um impacto profundo no campo educacional, sendo uma de suas manifestações mais evidentes a mudança produzida nas promessas oficiais referentes ao papel econômico desempenhado pela escola" (GENTILI, 1998, p.78). Tal influência pode ser atribuída além de outros fatores, às trocas culturais e às pressões dos grandes centros produtores de novos mercados de consumo.

Sob a égide da chamada globalização, na reestruturação produtiva os rígidos modelos de produção taylorista/fordista foram substituídos por um modelo de produção mais flexível, o toyotismo. Predomina hoje, o argumento de que a rigidez daqueles modelos estava comprometendo o crescimento do capitalismo, e que isso veio culminar numa crise econômica mundial - a qual têm servido de pressuposto para inúmeras mudanças nos âmbitos políticos, econômicos e sociais.

A sociedade contemporânea, particularmente nas últimas

duas décadas, presenciou fortes transformações. O

Educ. e Filos., Uberlândia, v. 21, n. 42, p. 193-226, jul./dez. 2007. 
neoliberalismo e a reestruturação produtiva da era da acumulação flexível, dotados de forte caráter destrutivo, têm acarretado, entre tantos aspectos nefastos, um monumental desemprego, uma enorme precarização do trabalho e uma degradação crescente na relação metabólica entre homem e natureza, conduzida pela lógica societal voltada prioritariamente para a produção de mercadoria, que destrói o meio ambiente em escala globalizada (ANTUNES, 2001, p.35).

A crise econômica se caracteriza por uma crise estrutural do capitalismo, ou seja, a configuração característica deste sistema nas ultimas décadas, acentuou sua lógica destrutiva. Nesse contexto desenham-se certas tendências, que podem assim ser resumidas:

1) o padrão produtivo taylorista e fordista vem sendo crescentemente substituído ou alterado pelas formas produtivas flexibilizadas e desregulamentadas, das quais a chamada acumulação flexível e o modelo japonês ou toyotismo são exemplos; 2) o modelo de regulação social-democratico, que deu sustentação ao chamado estado de bem-estar social, em vários paises centrais vem também sendo solapado pela (des)regulação neoliberal, privatizante e anti-social (ANTUNES, 2001, p.37).

As práticas culturais e político-econômicas nas sociedades contemporâneas se reconfiguram em vista do chamado sistema de acumulação flexível confrontando-se com a rigidez do modelo fordista determinando transformações nos processos de trabalho, nos produtos, e padrões de consumo com o auxílio direto de amplos e variados sistemas de informação e comunicação. Um exemplo disso é a flexibilização dos contratos de trabalho, maior mobilidade geográfica, respostas mais flexíveis aos mercados de trabalhos e etc.

Offe (1984) ao expressar pouco otimismo sobre a relação entre sistema educacional e sistema ocupacional afirma tratar-se de uma problemática estrutural do sistema capitalista, o que leva a pensar o mercado de trabalho como não mais capaz por si só, de resolver 
as demandas impostas pela sociedade contemporânea e caminha para o "fim dos empregos" (empregabilidade). A tese de Claus Offe é de que a relação funcional entre sistema educacional e sistema ocupacional implicam considerar que a força de trabalho subordina-se a critérios duplos e contraditórios (conhecimento para determinadas profissões e metacapacitação ou poder ajustar-se ao ritmo da transformação técnica, e econômica). A idéia de regulação da qualificação através do sistema de educação formal supõe sempre uma discrepância prática, temporal e pessoal (p.23). Este autor ressalta que:

[...] o que se coloca no cerne da análise sociológica orientada para a compreensão da escola, da universidade e da educação profissional dentro da sociedade global não é o que, e nem de quem partem as intenções que orientam o sistema educacional e sua reforma, mas que estruturas ele cria e transforma - e a que interesses ele está aberto e a quais permanece fechado. (OFFE, 1990, p. 12).

O impacto deste processo no campo educacional conduz a um deslocamento da ênfase na função da escola como âmbito de formação para o pleno emprego - "desintegração da promessa integradora" - para o âmbito de formação profissional competitivo para o da concorrência pelo emprego - promessa da empregabilidade. Isso implica para o trabalhador, a construção de uma nova esperança no interior de um contexto estruturalmente excludente característico dos novos tempos.

Mais do que pensar a integração dos trabalhadores ao mercado de trabalho, o desenho das políticas educacionais deveria orientar-se para garantir a transmissão diferenciada de competências flexíveis que habilitem os indivíduos a lutar nos exigentes mercados laborais pelos poucos empregos disponíveis. A garantia do emprego como direito social (e sua defesa como requisito para as bases de uma economia e uma vida política estável) desmanchou-se diante da nova

Educ. e Filos., Uberlândia, v. 21, n. 42, p. 193-226, jul./dez. 2007. 
promessa de empregabilidade como capacidade individual para disputar as limitadas possibilidades de inserção que o mercado oferece (GENTILI, 2002, p.89).

Disso decorre que,

morta definitivamente a promessa do pleno emprego, restará ao indivíduo (e não ao Estado, às instancias de planejamento ou às empresas) definir suas próprias escolhas que permitam (ou não) conquistar uma posição mais competitiva no mercado de trabalho (GENTILI, 2002, p.81).

Ou ainda,

[...] busca-se afirmar uma consciência alienada de que os vencedores ou os incluídos devem-no a seu esforço e competência. Os excluídos, os derrotados ou os miseráveis do mundo pagam o preço de sua incompetência (...). A crise do trabalho assalariado, entendida como o aumento exponencial do desemprego estrutural e precarização do trabalho, constitui-se num dos problemas políticos e psicossociais mais agudos da historia humana e, ao mesmo tempo explicita uma das contradições mais profundas deste fim de século. A classe trabalhadora que sempre lutou pela redução da jornada de trabalho e liberação do tempo livre empenha-se, hoje, desesperadamente para manter-se empregada mesmo às custas da perda de direitos duramente conquistados (FRIGOTTO, 2002, p.14).

A população é incentivada a não esperar mais do Estado e de suas políticas públicas, que garantem alguns direitos sociais - neste caso, emprego - e sim buscar viabilizar-se por si mesmo, no mercado num contexto de luta pela vida; também fora estimulada a imaginar um mundo, no qual as oportunidades aparecerão naturalmente e que seriam estruturadas pela concorrência, pela incerteza, pela mobilidade social, num quadro meio darwinista, em que os "ditos 
melhores", os mais determinados, os qualificados e empreendedores teriam tudo para progredir (NOGUEIRA, 2004). Pois,

[...] a vida coletiva passou a ser pensada como se estivesse na dependência exclusiva do acaso ou do esforço pessoal - quem sabe de alguma 'janela de oportunidade' aberta pelo mercado ou pelo empreendedorismo -, pouco importando se a resolução de problemas e de conflitos sociais pressuponha, pela lógica, uma dinâmica decisivamente social (NOGUEIRA, 2004 p.48).

Predomina, assim, uma lógica em que as políticas públicas sociais do Estado voltadas para o pleno emprego são gradativamente desregulamentadas pela falência do modelo de Estado interventor na esfera produtiva, e do modelo baseado na produção em massa, que caracterizou a crise dos anos 70 . Da mesma forma, de acordo com Del Pino, este não é um dilema recente na estrutura capitalista.

A crise da década de 70 foi a expressão do esgotamento de um modelo baseado na produção em massa, de um lado, e no chamado Estado de Bem-estar social, de outro. As condições que prevaleciam nos anos 30 e que surgiram periodicamente desde 1973 têm de ser consideradas manifestações típicas de tendências de superacumulação (2001, p. 67).

Tem-se, assim um modelo que se apóia "na flexibilização dos processos de trabalhos, dos mercados de trabalho, dos produtos e padrões de consumo" (HARVEY, 1992, p.140 apud DEL PINO, 2001 p.67), caracterizado pela flexibilização da produção denominado de toyotismo, e em especial da flexibilidade profissional que seria garantida por meio das propostas de reformas do ensino, entre outras.

As mudanças de paradigma no campo social orientadas pelo imperativo da globalização/flexibilização estão diretamente 
articuladas às transformações do mundo produtivo. Em linhas gerais, vivemos a emergência de novos paradigmas para o mundo produtivo, os quais refletem novas perspectivas para a relação trabalho-formação. Para Antunes (2001), o toyotismo pode ser entendido como um contraponto à rigidez fordista e aos princípios da administração taylorista. Antunes aponta as características básicas deste modelo de organização da produção.

1) produção muito vinculada à demanda; 2) ela é variada $\mathrm{e}$ bastante heterogênea; 3) fundamenta-se no trabalho em equipe, com multivariedades de funções; 4) tem como princípio just in time, o melhor aproveitamento possível do tempo de produção e funciona segundo o sistema de kanban, placas ou senhas de comando para reposição de peças e de estoque que, no toyotismo, devem ser mínimos. Enquanto na fábrica fordista cerca de $75 \%$ era produzido no seu interior, na fábrica toyotista somente cerca de $25 \%$ é produzido no seu interior. Ela horizontaliza o processo produtivo e transfere a "terceiros" grande parte do que anteriormente era produzido dentro dela (ANTUNES, 2001 p.42).

A forma "flexibilizada de acumulação capitalista", do modelo de produção japonês, teve conseqüências no mundo do trabalho como um todo e tais conseqüências se configuram no que podemos chamar de crise no mundo do trabalho, que se manifestou a partir do surgimento da acumulação flexível capitalista, a qual criou uma ideologia que tende a inverter a lógica da dependência, submetendo o trabalho e o trabalhador flexível à nova lógica de acumulação capitalista.

Neste sentido, desregulamentação, flexibilização, terceirização, downsizing, 'empresa enxuta', bem como todo esse receituário que se esparrama pelo 'mundo empresarial', são expressões de uma lógica societal onde se tem a prevalência do capital sobre a força humana de trabalho, que é considerada somente na exata medida em que é 
imprescindível para a reprodução deste mesmo capital. Isso porque o capital pode diminuir o trabalho vivo, mas não eliminá-lo. Pode intensificar sua utilização, pode precarizá-lo e mesmo desempregar parcelas imensas, mas não pode extingui-lo (ANTUNES, 2001 p.44).

Podemos considerar que a crise no mundo do trabalho trouxe, para a classe trabalhadora, a fragmentação e também a complexificação da sua relação com o processo de trabalho.

Criou-se, de um lado, em escala minoritária, o trabalhador "polivalente e multifuncional" da era informacional, capaz de operar com maquinas com controle numérico e de, por vezes, exercitar com mais intensidade sua dimensão intelectual. E de outro lado, há uma massa de trabalhadores precarizados, sem qualificação que hoje está presenciando as formas de part-time, emprego temporário, parcial, ou então vivenciando o desemprego estrutural (ANTUNES, 2001, p.44).

Tem-se assim, a cisão da classe trabalhadora provocada pela reestruturação produtiva, fato esse que fez com que parte da classe proletária buscasse no emprego informal seu sustento e sobrevivência. Já para uma minoria desenvolveu-se o mito, de que a qualificação seria a porta de inclusão ao mercado de trabalho. Difundiu-se, desse modo, a idéia do investimento no capital humano como garantia de melhores empregos, mobilidade e ascensão social.

Hoje a educação formal e a qualificação são situadas como elementos da competitividade, reestruturação produtiva e da 'empregabilidade', [pois] já não há políticas de emprego e renda dentro de um projeto de desenvolvimento social, mas indivíduos que devem adquirir competências ou habilidades no campo cognitivo, técnico, de gestão e atitudes para se tornarem competitivos e empregáveis. Os desempregados devem buscar 'requalificação' e 'reconversão profissional' para

Educ. e Filos., Uberlândia, v. 21, n. 42, p. 193-226, jul./dez. 2007. 
se tornarem empregáveis ou criarem o auto-emprego no mercado informal ou na economia de sobrevivência (FRIGOTTO, 2002, p.15, grifo nosso).

A globalização da informação vem promovendo uma homogeneização da cultura e das experiências e valores significativos de cada indivíduo, alterando também a integração desses indivíduos ao mundo do trabalho através da redefinição da qualificação profissional, e isso se expressa nas inúmeras políticas de reformas educacionais sob a influência dos processos e cenários sociais e mudanças estruturais do capitalismo mundializado. Catani; Oliveira; Dourado, 2001 mostram que é possível compreender as transformações do mundo do trabalho e, conseqüentemente, os processos de produção, organização e formação a partir da relação entre os cenários de mudanças no mundo da produção e o nível de qualificação dos recursos humanos. Da mesma forma, em decorrência há estreita relação entre o desenvolvimento científico e tecnológico e a importância da formação e da produção do conhecimento no desenvolvimento da produtividade.

Diante da emergência do cenário acima apresentado colocase a importância de uma análise que tome como categoria a questão da flexibilização no que se refere à formação universitária, reestruturação produtiva e mercado.

\section{Reforma do Estado, reforma do ensino superior e princípios curriculares}

Os rumos dos processos de mobilização, normatização, institucionalização e gestão das reformas do ensino superior desencadeados pelos órgãos do poder central nos instigam a considerar o sentido das tensões e relações contraditórias que permeiam as reformas educacionais articuladas à reforma do Estado.

No contexto educacional nacional, observamos que o Estado, através de órgãos executivos e legislativos, tem interferido no ensino 
superior via reformas sociais com fortes características técnicoburocráticas. Sua atuação, nesse âmbito, se expressa em vários aspectos, tais como no financeiro, na organização do ensino e nas diretrizes curriculares. Significa dizer que o Estado dispõe e regula a forma de concretizar esse nível de ensino sem deixar margem de autonomia para que sociedade e instituições educacionais possam ir além da função de meros executores e participar dos processos de definição e planejamento das reformas. Tais intervenções se exercem em forma de controle, também, no plano simbólico-cultural, pelo qual o Estado delineia sua política cultural para assegurar a difusão de valores dominantes (CORRÊA, 2000). Isso porque, quanto à política de reforma educacional, observa-se, entre autores e gestores, a opção por certos saberes em detrimento de outros que se valem, para tanto, de uma concepção epistemológica com forte tendência ideológica. Para garantir êxito na difusão de tais valores, são acionados mecanismos, sujeitos e instituições - como sistema escolar, professores e instrumentos legais (POPKEWITZ, 1997).

A partir da categoria dimensão ampliada de Estado (GRAMSCI, 1991) podemos considerar que o Estado propaga seu ideário por meio de seus aparelhos de hegemonia, e instituições sociais como universidades e escolas que têm a função não só de elaborar, como também de difundir visões de mundo a serviço do projeto do Estado capitalista. Assim, o movimento de reformas educativas nas instituições e no mundo escolar passa pela mediação do Estado e está marcado por conflitos travados na sociedade, daí o papel fundamental das contradições na emergência e construção de uma contra-hegemonia dos sujeitos frente às prescrições advindas do poder e do controle estatal. Podemos considerar que o Estado se insere nas relações sociais de classe e integra uma síntese dialética que envolve sociedade civil e sociedade política numa disputa constante pelo poder. Isso nos permite tomar como premissa que a universidade como instituição social reflete as contradições emergentes da relação de hegemonia entre universidade, sociedade e realidade; ou seja, não apenas tem uma intervenção na realidade na qual se insere, mas também reflete contradições geradas nos amplos movimentos sociais.

Educ. e Filos., Uberlândia, v. 21, n. 42, p. 193-226, jul./dez. 2007. 
Nesse contexto, tem relevância uma análise sobre o papel do Estado como mediador na correlação de forças quanto às exigências das reformas educativas. Em tal correlação, travada entre Estado e sociedade, são formuladas políticas governamentais especificamente no interior dos órgãos formuladores e gestores de diretrizes das políticas educacionais em nível macro (MEC/CNE e organismos multilaterais), implementadas por outros gestores (instituições de ensino) em nível intermediário/micro.

No que se refere às políticas educacionais de reforma do ensino superior dos anos de 1990 definidas pelo MEC, observa-se que, em decorrência de mudanças impostas por tais políticas, encontra-se instaurado no interior das IES um quadro marcado por tensão e perplexidade. A intervenção estatal na reconfiguração da universidade no momento atual é uma tendência que se manifesta nas reformas, independentemente dos interesses dos profissionais da educação e dos interesses da sociedade.

A reformulação curricular do ensino de graduação é, assim, parte dessa tendência em estreita vinculação com a reforma do Estado. Ela se efetiva, portanto, pela lógica do processo de mudança que se impõe para a educação superior sob orientação da tendência político-econômica de caráter mercadológico. Ao assumir uma perspectiva de classe, o Estado brasileiro progressivamente se reconfigura, rumo a um Estado avaliador e regulador na formulação e condução de políticas neoliberais dominantes. Isso evidencia seu novo papel, sua opção e seus interesses, em vista do âmbito do capital por meio de seu enxugamento, sua revisão, sua minimização e, sobretudo, pela privatização dos serviços sociais, que passariam a ser produzidos e autogeridos pelas Organizações Sociais - dentre os quais, o compromisso com a universidade pública.

Na relação entre o papel do Estado e a reforma do ensino superior ora em processo de implantação, de acordo com Silva Júnior, é possível afirmar que se trata de

[...] uma intervenção consentida e realizada pelas autoridades educacionais orientadas pelas agências multilaterais, no contexto da universalização do capitalismo, direcionadas por 
uma razão instrumental, que se constitui no epicentro de um processo de mercantilização do trabalho imaterial, em geral, e em particular, da esfera educacional em seu nível superior. (SILVA JUNIOR, 2003, p. 61).

Como um dos principais mediadores do movimento das reformas neoliberais, o Estado busca organizar a economia e a sociedade segundo orientações do contexto de expansão e universalização do capitalismo em nível internacional - embora isso se dê em meio a tensões e contradições decorrentes de sua minimização e da centralização do poder de decisão (SILVA JÚNIOR, 2003, p. 75). Esse movimento não é, portanto, um fato isolado: insere-se no contexto amplo das reformas empreendidas na América Latina e é mediado pelos órgãos do Poder Executivo, representado pelo MEC, e por outros criados especificamente para este fim, como o Ministério da Administração e Reforma do Estado (MARE).
A primeira grande meta da reforma do aparelho do Estado é [...] a sua flexibilização. Em segundo lugar, no plano social, é a sua radical descentralização. A eficiência, agilidade etc. dos serviços do Estado deveriam ser semelhantes às do setor privado. Para isso procura apresentar uma forma de administração "mais flexível do que a adotada no núcleo burocrático da administração direta" e encontra-a, principalmente, no projeto das "organizações sociais" [...]. Daí a necessidade de sua [do Estado] urgente reforma para maior flexibilização da administração [...]. (SGUISSARDI; SILVA JÚNIOR, 1997, p. 12).

Pelo exposto é possível compreender, que as ações patrocinadas e orientadas pelas recomendações e diretrizes metodológicas do Banco Mundial-BM constituem exemplo claro da redefinição do papel do Estado - conforme sugere o documento Prioridades e Estratégias para a Educação: Estudo Setorial do Banco Mundial, de 1995, que se tornou célebre como referência oficial à reforma

Educ. e Filos., Uberlândia, v. 21, n. 42, p. 193-226, jul./dez. 2007. 
do ensino superior no Brasil. Explicitam que tais ações deveriam objetivar a uma maior agilidade na administração pública e, sobretudo, à perspectiva de flexibilidade nos padrões de atuação do Estado no que refere às diretrizes para ensino na universidade.

Pimenta (1998) destaca como fator determinante das perspectivas mundiais das reformas educacionais, a nova configuração e as características das políticas sociais que têm se expressado na tendência modernizadora que se configura com o novo papel do Estado. Nas palavras desse autor,

Um dos principais fatores de aceleração no processo de transformação do Estado é o atual contexto das grandes tendências mundiais relacionadas à globalização, a progressos na tecnologia da informação e à emergência da sociedade civil organizada. Neste momento o Estado está abandonando algumas funções e assumindo outras, o que o está levando a um novo papel, onde o setor público passa de produtor direto de bens e serviços para indutor e regulador do desenvolvimento, através da ação de um estado ágil, inovador e democrático. (1998, p. 173).

No caso do Brasil, a atual reforma da educação superior, iniciada nos anos de 1990, tornou-se um dos alvos privilegiados das intervenções e do controle do Estado via projetos e planos de políticas reformistas modernizadoras do próprio Estado e da universidade. O que marcou o processo de inserção do Brasil no contexto de modernização neoliberal foi o plano de governo Collor - Projeto de Reconstrução Nacional (1991), com a implementação do projeto de reforma e modernização do Estado e os planos decorrentes (Plano Decenal e Plano Diretor) -, que criou em 1995 o Ministério da Administração e Reforma do Estado (MARE), especialmente, para implementar a reforma do Estado (BRITO, 1999: 23). Nesse sentido, cabe reiterar que tal processo foi estrategicamente patrocinado pelos organismos multilaterais: elementos de extrema importância nos rumos trilhados pelas reformas educativas brasileiras. Nesse caso, as reformas e as 
mudanças que se pretenderam efetivar com elas têm ocorrido no bojo do processo de crise e modernização do Estado e em vista da redefinição de seu papel social. Em outras palavras, o caráter das reformas brasileiras tem se definido conforme os compromissos assumidos pelo governo na agenda dos eventos e acordos internacionais que determinam linhas básicas para as políticas educacionais dos países da América Latina.

É preciso considerar, portanto, que as reformas curriculares em implementação no ensino superior brasileiro não fogem a esse procedimento. Isso porque se concretizam por meio de ajustes cujo fim é redefinir as funções da educação superior, sobretudo nas IFES, para adequá-la ao contexto político-econômico que se reconfigura em decorrência da crise do capitalismo mundial. Segundo análises de Dourado e Oliveira, a educação superior

[...] parece ser chamada a contribuir em duas tarefas que historicamente constituem funções básicas da universidade: conhecimento e formação profissional, ou melhor produção do conhecimento e formação profissional. Essas duas áreas são consideradas, atualmente, fundamentais para a inserção de qualquer país no processo competitivo do mundo globalizado [...]. Essa lógica interfere nas políticas de educação superior, particularmente, nos novos padrões de gestão, financiamento e na organização do trabalho acadêmico. (1999, p. 12).

Na efetivação das reformas derivadas da modernização do Estado brasileiro, predominam um discurso e uma prática de ações legitimadoras de políticas enfáticas na modernização educacional em função de mudanças no modo de organizar o setor produtivo via intervenção estatal nos processos de formação como prerrogativa delineada em eventos e programas assumidos na agenda internacional. Isso se reflete na nítida alteração de padrões de financiamento da educação pública, assim como na adoção de novas formas de gestão e implementação de mecanismos de avaliação e controle das instituições educacionais (DOURADO; OLIVEIRA, 1999).

Educ. e Filos., Uberlândia, v. 21, n. 42, p. 193-226, jul./dez. 2007. 
Ao analisar a redefinição e modernização das funções do Estado como imperativo das políticas externas, Pimenta (1998) ressalta que, pela lógica das políticas sociais predominantes, para o Estado desempenhar bem seu papel,

[...] é preciso que o mesmo também redefina suas funções junto à sociedade, para ser coerente com o projeto pelo qual optou - o projeto neoliberal - pois este exige um Estado ágil, inovador e democrático, uma vez que - nesta ótica - as principais funções desta instituição deverão ser a regulação, a representatividade política, a justiça e a solidariedade. (1998, p. 174).

Aqui, o novo papel do Estado se define na perspectiva de um Estado modernizado cujo perfil é determinado por orientações da política externa com prioridade para necessidades mercadológicas em detrimento de demandas sociais e educacionais do país. Com a reestruturação do setor produtivo e o surgimento de novos modelos de organização do trabalho, surgem formas de relações trabalhistas que demandam, igualmente, a modernização estatal e a conseqüente redefinição do papel do Estado no setor produtivo e na sociedade.

As principais funções deste novo Estado são a regulação, a representatividade política, a justiça e a solidariedade. [...] há um consenso de que será necessário reformar o Estado e que para tanto existem muitos caminhos possíveis, geralmente baseados em um dos três grandes dogmas institucionais da nossa época: o mercado, o Estado e a comunidade. Nenhuma destas instituições pode enfrentar sozinha os desafios impostos para a reforma do Estado. Será necessária a articulação destas três instâncias, sem falácias (como aponta Claus Offe, 1998), pois o neoliberalismo, o estatismo e o comunitarismo, cada um isoladamente, não serão a solução para a construção de novos paradigmas sociais. (PIMENTA, 1998, p. 174). 
A nova configuração estatal é, então, parte do processo histórico das tendências mundiais das políticas globalizadas nas quais as reformas integram novos elementos, novos pressupostos para estruturação e organização de instituições da administração pública e, por conseguinte, para configuração da universidade, constituindo fator de integração do país ao cenário mundial. Ganham sentido, assim, expressões como: "desburocratização, descentralização, transparência, accountability, ética profissiona-lismo, competitividade e enfoque no cidadão" (PIMENTA, 1998, p. 174). Logo, esse processo caracteriza uma nova modalidade de acumulação, uma nova concepção do poder e do papel do Estado e do discurso modernizador que orienta as reformas da educação superior.

Nessa mesma linha de análise, Draibe vê a modernização do Estado como condição fundamental à inserção do Brasil na economia mundial nos anos de 1980 e 1990, articulada com as proposições das políticas sociais neoliberais. Esse processo demarcou a intensificação do movimento de reformas que desobrigou o Estado de seu papel no campo socioeducacional, sobretudo ao sugerir as "organizações públicas não-estatais" como modelo de IES para o país. (DRAIBE, 1993, p. 86-101).

Segundo Marques, o processo de reconfiguração da universidade mediante redefinição do papel do Estado se caracteriza, sobretudo, pelas intervenções do MEC.

As recentes ações do Ministério da Educação visando alterar o estatuto das Universidades Federais brasileira têm sido objeto de um amplo debate em torno do tema crucial da autonomia institucional, sobretudo, após a apresentação pelo MEC, em 29 de julho de 1999, do projeto de lei que dispõe sobre a autonomia das universidades federais e que vem confrontarse com o artigo 207 da Constituição, que tem por princípio a autonomia universitária. (MARQUES, 2000a, p. 219).

Nesse contexto, Marques (2000) considera, ainda, a relação entre autonomia e crise de identidade docente inserida no movimento reformista do Estado e da educação, e destaca que 
Um dos fatores primordiais dessa crise é a reconfiguração da identidade do próprio Estado-nação na atual fase do capitalismo globalizado; o fundamento político-ideológico dessas alterações são os princípios e processos de modernização, racionalização, qualidade, 'flexibilização' e 'autonomia'. (2000a, p. 221).

Ainda com enfoque no elemento-chave da retórica presente no discurso e nas ações da reforma empreendida na educação superior, Marques vê como necessária a explicitação de significados e finalidades que a questão da autonomia procura abranger.

A compreensão do embate em torno da questão da autonomia requer algumas considerações preliminares: 1) O tema autonomia tem se tornado recorrente na proporção do avanço do paradigma da flexibilização das relações de trabalho, da privatização, desestabilização e/ou "publicização" das instituições públicas, bem como da racionalização administrativa do Estado; 2) A tendência retórica e política dessas práticas sociais extrapolam o setor universitário, atingindo todo o sistema de educação nacional e seus respectivos atores educativos, através de uma ampla reforma educacional conduzida pelo MEC e pelos principais governos estaduais, associada às políticas racionalizadoras, do Ministério da Administração e Reforma do Estado, e sob orientação incontestável dos mega-atores intelectuais da cena mundial na atualidade, como o Fundo Monetário Internacional, o Banco Interamericano de Desenvolvimento, o Banco Mundial, etc.;3) Uma vez que universidades e escolas não são entidades abstratas, mas espaços-tempo de relações sociais, os efeitos de tais tendências político-institucionais recaem sobre o estatuto das pessoas, ou seja, nas subjetividades-profissionais de professores, técnicos, dirigentes, etc.; 4) Esse processo tem contribuído para engendrar um quadro de perplexidade no meio educacional, aprofundando uma crise de identidade profissional e/ou um 
mal-estar docente que tende a suscitar a discussão em torno da autonomia profissional. (MARQUES, 2000a, p. 219-220).

O padrão de modernização que orienta o atual papel do Estado em estreita relação com as políticas educacionais tem determinado a finalidade da reforma curricular que ora vivenciamos na universidade, assim como definido sua base na emergência do paradigma centrado na idéia de flexibilização e autonomia inter-relacionadas, como em outros setores da vida econômica e política do país. Pois,

[...] especialmente no âmbito cultural-simbólico, a ação do Estado educador nos acordos da modernização é pautada na epistemologia do processo ou melhoramento social e, portanto, mediada pelo regime geral de valores, como um dos pressupostos da gestão do moderno contrato social, isto é, um dos principais fatores de legitimação do próprio Estado moderno. (MARQUES, 2000b, p. 227).

Nesse sentido, pode-se considerar como implícita nesse discurso modernizador uma pedagogia que reforça propósitos da mudança educacional pelas reformas modernizadoras do Estado brasileiro. Marques ainda observa que as reformas são, implicitamente,

[...] processos de regulação social, institucional e individual conforme o padrão histórico da mudança operada no espaçotempo estatal, enquanto que explicitamente, são respostas a expectativas públicas de modernização operadas pelo Estado condutor, num contexto de validação simbólico-cultural definida pela idéia de "crise". Por seu turno, a reforma educacional é um mecanismo explícito de mobilização pública que opera no nível superestrutural, para a reforma implícita do Estado e das bases materiais produtivas que ocorre no nível estrutural. Essa mobilização pública pela reforma educacional tem como epicentro a figura histórica universal e generalizante do magistério e do professor. (MARQUES, 2000b, p. 227).

Educ. e Filos., Uberlândia, v. 21, n. 42, p. 193-226, jul./dez. 2007. 
A reforma da educação superior no Brasil parece configurar uma situação de controle social, por parte de órgãos estatais, nas instituições formadoras da identidade social e profissional. Por ser uma interrelação que envolve poder, conhecimento e instituições, pode-se reconhecer as implicações dessa mudança sócio-educacional como uma pedagogia a serviço do poder estatal, que opera nas subjetividades dos sujeitos (MARQUES, 2000b, p. 227).

Dias Sobrinho (2003) ressalta que o poder sobre as universidades brasileiras é exercido como controle em que se usam, dentre outros, procedimentos avaliativos, por exemplo, o poder fiscalizador do Estado prioriza resultados em detrimento de processos e serviços educacionais, sobretudo ações que impliquem recursos públicos sem retorno lucrativo para o setor privado. Esse autor examina as principais características da educação superior como processo de "economização da educação", dentre as quais, "o crescente controle do Estado sobre o produto".

O Estado, em grande parte, abre mão dos processos, liberaliza as condições de criação e expansão de instituições. Estas se tornam mais livres e flexíveis para desenvolver serviços e atividades que absorvam mais ajustada e facilmente as demandas do mercado. A flexibilidade é conferida aos processos, aos meios, à administração descentralizada, às relações contratuais, com o propósito de facilitar a gestão eficiente, aumentar a produtividade e ampliar as liberdades para a expansão privada. A esta flexibilização assim concebida, como liberalização dos processos, corresponde a atual noção de autonomia, isto é, liberdade em reação aos meios, para obtenção de maiores resultados. Entretanto, a autonomia assim delimitada é negada pela avaliação, a qual, deturpando o sentido formativo que é próprio das atividades educacionais, identifica-se quase somente com o controle dos resultados. Segundo a lógica do mercado e a competitividade incentivada pelos Estados, os processos têm de ser livres; as instituições educacionais, como as empresas comerciais, precisam de liberdade para se estabelecerem e aumentarem sua eficiência e produtividade. (DIAS SOBRINHO, 2003, p.105). 
As proposições da reforma, por meio de diretrizes do MEC/CNE, para flexibilizar os currículos do ensino de graduação evidenciam uma importante contradição no papel do Estado. Isso porque, através de políticas reformistas orientadas pela suposta idéia de autonomia da universidade em relação ao controle (avaliação), verifica-se que

O mais rígido controle do Estado sobre a sociedade não se dá propriamente sobre a esfera econômica, pois esta requer ampla liberdade para se desenvolver competitivamente, na ótica neoliberal. O controle é principalmente sobre o campo social e do simbólico, campo de valores disputados, onde se aloja a educação. Aqui intervém o conceito de qualidade tributária das noções de eficiência, produtividade, competitividade. Os Estados julgam fundamental assegurar que a educação seja eficiente à economia da vida capitalista e, portanto, tratam de garantir que as instituições busquem a excelência na formação profissional dos estudantes e na consecução das competências e habilidades formuladas para o domínio geral. O rígido controle central sobre o campo social e a esfera do simbólico, particularmente no âmbito do sistema de educação, incide também no nível de cada instituição em particular. (DIAS SOBRINHO, 2002, p. 20).

No contexto atual, as reformas marcadas pelo discurso da flexibilização - apresentada como sinônimo de ampla liberdade (autonomia) para as instituições redefinirem, dentre outras coisas, sua estrutura curricular, conforme preconizam as orientações oficiais - apresentam uma perspectiva contrária à autonomia defendida historicamente pelos educadores, a saber, uma autonomia que: assegure o papel da universidade na produção e socialização do conhecimento; inclua interesses e necessidades da sociedade e possibilite flexibilizar os currículos mediante princípios, proposições e práticas democráticos.

Diferentemente, autonomia universitária para o Poder Executivo integra um conceito carregado de intenções político-ideológicas cujo

Educ. e Filos., Uberlândia, v. 21, n. 42, p. 193-226, jul./dez. 2007. 
pano de fundo é a lógica que atribui à educação função econômica estreitamente voltada às necessidades do mercado. "Se a qualidade é representada pelos resultados objetivos, a avaliação é tomada por controle desses produtos, associados à flexibilização de formas, tempos, contratos, fontes de financiamentos e outros itens relativos à noção de eficiência como noção economicista" (DIAS SOBRINHO, 2002, p. 108). Logo, observa-se que o sentido de determinadas expressões como autonomia se esvaziam, perdem a essência.

O conceito de autonomia vem sofrendo um desvio semântico que toca sua essência. Se o mercado define os perfis profissionais e os tipos de conhecimento que têm utilidade e preço, se as políticas e prioridades educacionais são elaboradas pelos governos e determinadas às instituições e aos sistemas, que as devem executar eficientemente, já não se pode mais falar, com propriedade, de autonomia universitária. Resta às instituições cumprir o que está valorizado e determinado externamente. Cabe-lhes submeterse aos processos externos de comprovação de resultados, $a$ posteriori, tais como exames e avaliações, que funcionam como controle de qualidade, com base sobretudo em descrições quantitativas de sua infra-estrutura e de seus produtos. Neste caso, interessam pouco os processos que produziram tais resultados, a pertinência e relevância social, as dificuldades e potencialidades (DIAS SOBRINHO, 2002, p.20).

Além de numerosas expressões se integrarem à linguagem das reformas, vivenciamos uma ressignificação do universo conceitual em vista dos discursos, das ações e dos procedimentos, demonstrando negação da própria autonomia em sua forma e dimensão ampla e democrática.

Entendida como uma ideologia que engendra ações concretas, que altera substancialmente, o modo de ser e o cotidiano das instituições educacionais. [...] Essa ideologia opera mudanças no ensino, relativamente ao currículo, às atividades didático- 
pedagógicas e à profissionalização do docente. Submete a pesquisa ao critério de utilidade imediata requerida, sobretudo pela indústria. Assim, a universidade e seus pesquisadores perdem prerrogativa de definir as prioridades não só do currículo, mas também da pesquisa. Alteram-se as relações das instituições com o Estado e com a sociedade. (DIAS SOBRINHO, 2002, p.15).

Assim, a ressignificação que orienta as transformações atuais da educação superior mostra a dimensão ideológica das reformas quanto a reforçar a privatização. A universidade deve "responder às exigência imperativas de um e atender às demandas contraditórias da outra, de modo particular àquelas que se referem às novas exigências que brotam das forças do mercado e das transformações no mundo do trabalho" (DIAS SOBRINHO, 2002, p. 15), de modo a redefinirem a identidade atual das universidades determinando novas funções para o ensino superior.

Com a reformulação curricular, a formação acadêmica adquire um significado pragmático, que a torna aligeirada, superficial e imediatista, como um ideal de identidade a ser construído pela formação profissional. Isso porque as perspectivas que se delineiam para as reforma do ensino de graduação mostram claramente a opção pelo paradigma da flexibilização neoliberal: ideário que ganha centralidade nas proposições do MEC. O enfoque teórico é de caráter ideológico e enfatiza uma concepção pedagógica centrada na flexibilização da formação; o profissional deve ter perfil flexível e apto a responder às rápidas mudanças do setor produtivo e suprir suas necessidades; assim como características pessoais e sociais que lhe permitam se adequar à flexibilização da organização do mercado de trabalho.

Por fim, cabe assinalar que as reflexões aqui desenvolvidas, ao tomar como categorias chaves a flexibilização para analisar a relação entre a reforma do Estado e as políticas educacionais, podemos concluir que o movimento reformista no Brasil explicita seu verdadeiro significado nas relações contraditórias entre sociedade, instituições de ensino e Estado no contexto da 
reconfiguração do Estado brasileiro. A reforma do ensino superior assume, dessa forma, um significado histórico cuja manifestação se caracteriza e se materializa mediante ações de órgãos oficiais articuladas com orientações de agências multilaterais que assumem papel preponderante na implementação das políticas reformistas. Ou seja, a reforma do ensino universitário resulta da reconfiguração do Estado em vista de seu papel no contexto de redefinição das estratégias de manutenção e expansão do capitalismo vinculado ao projeto neoliberal de minimização do Estado.

\section{Formação profissional e mercado: dilemas e paradoxos da flexibilização e autonomia}

Até aqui, esta análise evidenciou conforme a abordagem de Marques (2000a) a presença de um dilema entre flexibilização e autonomia na relação formação e mercado.

Ora, se por um lado tal dilema se expressa no movimento mais amplo das políticas de reconfiguração macroeconômicas relativas à reestruturação produtiva, que subordinam o setor educacional às regras do mercado e indicam uma relação entre processo de reforma e mercado de trabalho pelo princípio da flexibilização, por outro, esse dilema se expressa nos limites e nas possibilidades apresentadas pelo princípio da autonomia, indicando uma relação entre processo de reforma e autonomia profissional. Logo, buscar uma síntese do desenvolvimento das elaborações suscitadas na presente análise nos leva a depreender que a autonomia se define na medida "do avanço do paradigma da flexibilização das relações de trabalho" (MARQUES, 2000a, p. 219). Isso porque as tendências reformistas superam o âmbito propriamente institucional e "recaem sobre o estatuto das pessoas, ou seja, das subjetividades profissionais" (MARQUES, 2000a, p. 220).

Sobre a relação processo de reforma-mercado de trabalho pressupondo-se que o currículo é, em parte, responsabilizado pelas respostas às demandas do setor produtivo - é possível verificar no processo de reformulação curricular acerca da relação entre as mudanças propostas e a produção do perfil profissional na formação 
ante a atuação deste no atual contexto do mundo do trabalho. Tal visão se traduz em um questionamento: como a flexibilização curricular contribuiria para produzir um profissional capaz de suprir as demandas mercadológicas e quais seriam as implicações disso para a formação profissional? É possível afirmar, que há um grande interesse no âmbito acadêmico em abordar tal relação. Observa-se que se trata de um problema que demanda hoje uma resposta das instituições de ensino, o que impõe a necessidade de se desenvolver, com os alunos em formação, um trabalho sobre a inter-relação entre educação e complexidade do mundo do trabalho. Também ressaltam-se as implicações do contexto político-social e, sobretudo, das rápidas mudanças no mundo do trabalho decorrentes do processo de reconfiguração econômica capitalista e de suas determinações para a formação universitária.

Todavia, fica evidente que o modelo curricular, marcado pela flexibilização expressa uma relação direta entre formação e mercado de trabalho, por isso é considerada relevante e deve ser objeto de reflexão crítica quanto a princípios e finalidades no interior do projeto político pedagógico de reformulação curricular das IES. É relevante, ainda, porque possibilita refletir sobre o caráter contraditório entre reforma e possibilidades de inserção no contexto profissional de hoje. Contudo, há uma questão a ser compreendida, não para uma adesão passiva à lógica do mercado, mas para problematizá-la e desmistificá-la, tendo em vista o contexto de mudanças e de crise do trabalho em que vivemos.

Ainda que não possamos negar a existência - no âmbito acadêmico - de uma visão mercadológica impregnada na concepção da maioria dos professores e na expectativa dos alunos é possível perceber que esse caráter pragmático-ideológico se encontra, também, nas entrelinhas das diretrizes curriculares do MEC. Assim, é consenso que uma proposta curricular deve partir de uma concepção crítica da relação formação-mercado de trabalho, mas considera-se, também, que os questionamentos devem prever a inserção do futuro profissional na realidade atual e concreta que se delineia. Se as políticas educacionais desvalorizam a função social da educação, limitandoas a critérios que desvalorizam a formação do profissional, ainda que

Educ. e Filos., Uberlândia, v. 21, n. 42, p. 193-226, jul./dez. 2007. 
para isso o parâmetro seja aceitar ganhar menos e não o saber mais é inserido no mercado que o profissional poderá criar as condições concretas para a transformação desses parâmetros (SILVA, 2006).

Vista assim, a relação ensino universitário-mercado precisa ser problematizada no currículo, e isso deve se traduzir na formação acadêmica, pois o papel social da universidade deve incluir as necessidades sociais, e não apenas as leis do mercado. Logo, ao futuro profissional cabe compreender as contradições emergentes das relações sociais dentro e fora do mundo do trabalho, o que demanda dele uma postura crítica e transformadora sem abrir mão de seu espaço profissional nesse contexto.

Quanto à identidade profissional - a flexibilização aparece como princípio curricular oficial destinado à formação de profissionais flexíveis - porque detentores de autonomia - e pragmáticos - porque portadores de competências para resolver problemas. No que se refere à identidade institucional, os discursos e as práticas da reforma curricular destacam a perspectiva de construção autônoma de um projeto pedagógico institucional que limita as possibilidades de decisão e de seu desenvolvimento por meio de prescrições centralizadas que retiram da universidade seu papel de definir, de forma auto-referenciada, as bases da formação profissional.

Tem-se, assim, um paradoxo: embora integre o ideário políticopedagógico apresentado como inovador em seu conjunto, o princípio da flexibilização tal como propõem as orientações oficiais para as diretrizes curriculares - para imprimir maior autonomia às instituições formadoras, dando-lhes mais liberdade $\mathrm{e}$ adaptabilidade às rápidas mudanças do mundo produtivo atual fica comprometido, justamente, pelo princípio da formação orientada pelo desenvolvimento das chamadas competências. Isso porque estas, na verdade, traduzem um rígido controle dos comportamentos profissionais e institucionais por fins e processos padronizados e definidos a priori, articulados com procedimentos avaliativos.

Podemos afirmar, então, que na relação entre flexibilização e autonomia, flexibilizar pode ter, ao menos, dois sentidos que caracterizam certa ambigüidade: flexibilização/competências e 
flexibilização/autonomia - como possibilidade de maior ou menor grau de autonomia decorrente das concepções, proposições e ações imbricadas no processo de reformulação curricular. O sentido de flexibilização/competências é próprio do âmbito do instituído diga-se, dos dispositivos e procedimentos prescritivos de políticas oficiais em que a flexibilização, como princípio, é um elemento ou pressuposto mais ou menos constante, enquanto as competências são variáveis, porque dependentes do contexto das demandas econômicas e político-culturais do mercado. Assim, a tendência é a perda de autonomia. O sentido de flexibilização/autonomia é próprio do âmbito do instituinte - vale dizer, das resistências e lutas inerentes ao jogo de forças que envolvem os fóruns científicos e profissionais, bem como setores da sociedade, em relação às políticas oficiais em que a flexibilização e a autonomia são aspectos constantes porque qualidades do processo político-cultural social e, sobretudo, educacional. Logo, a tendência é o ganho de autonomia.

Tal constatação é coerente com a afirmação de que as relações entre Estado, instâncias governamentais e professores mediadas pelo conhecimento - ciências humanas e ciências da educação (inclusive formação, currículos e atuação profissional) - expressam uma "tensão histórica entre regulação e autonomia", na qual está em jogo "manter, ampliar ou perder autonomia" (MARQUES, $2000 a$, p. 223-24).

Não se trata de negar como princípio a flexibilização do modelo de formação vigente; reconhece-se que a estrutura curricular atual precisa ser revista ante o atual contexto social, político e econômico. Dados os limites e as perspectivas do modelo de formação, que podem assumir diferentes propósitos, o que está em questão é o pressuposto de que a flexibilização curricular deveria responder não só a demandas mercadológicas, mas também a princípios de um projeto sociopolítico participativo, democrático e historicamente contextualizado defendido de forma legítima pelos educadores como resposta às demandas da realidade educacional e social do país.

É possível supor que, nesse sentido, a tendência flexibilizadora contribui para levar as instituições universitárias a abandonar a

Educ. e Filos., Uberlândia, v. 21, n. 42, p. 193-226, jul./dez. 2007. 
autonomia didático-pedagógica e se renderem às premissas e ao poder das forças econômicas mercadológicas em detrimento de um processo de formação orientado pelo papel social e científico da universidade, pois as tensões/contradições sintetizadas no dilema flexibilização-autonomia se evidenciam como indícios de um possível impacto negativo da reforma curricular na identidade das IES/IFES.

Posto isso, podemos considerar que as proposições da reforma, no que diz respeito à relação entre perfil profissional e mercado, trás à tona a discussão sobre a formação, o que nos leva a avaliar que o ponto positivo do processo reformista foi a instauração de um clima propício a um diagnóstico que levanta problemas e cria oportunidade para se repensar esta formação acadêmica, que nunca foi objeto de reflexão mais ampla, em especial nas IES.

Não há como negar, portanto, no processo de implementação da reforma, a existência de uma tensão - permeada pela questão do poder - entre forças políticas e sociais quanto a propósitos, pressupostos e metodologia de implementação das diretrizes curriculares orientadas pelo princípio da flexibilização e pelo princípio da autonomia profissional e institucional. Assim, à medida que são formuladas por técnicos do poder central e reproduzidas pelo poder institucional, as reformas pouco têm a ver com as demandas do contexto acadêmico, com suas peculiaridades, com suas (re)configurações determinadas pelo movimento histórico, social, cultural e pedagógico, tanto interno quanto externo ao sistema educacional. Logo, é possível reconhecer que se trata de uma relação de tensão entre os princípios da flexibilização institucional e os princípios da autonomia profissional articulados às demandas do mundo do trabalho.

\section{Referências}

ANTUNES, Ricardo. Trabalho e precarização numa ordem neoliberal. In: FRIGOTTO, Gaudêncio; GENTILI, Pablo (Org.). A cidadania negada: políticas de exclusão na educação e no trabalho. São Paulo: Cortez; Buenos Aires, Argentina: Clacso, 2001. 
BRASIL. Lei $\mathrm{n}^{\circ}$ 9.394, de 20 de dezembro de 1996. Estabelece Diretrizes e Bases da Educação NACIONAL. Diário Oficial da União, Brasília, 1996.

BRITO, Vera Lúcia. A. Autonomia universitária. In: DOURADO E CATANI (Org.). Universidade pública: política e identidade institucional. Campinas: Autores associados; Goiânia: Editora da UFG, 1999.

CATANI, Afrânio; OLIVEIRA, João F; DOURADO, Luiz F. Política educacional, mudanças no mundo do trabalho e reforma curricular dos cursos de graduação no Brasil. Revista Educação e Sociedade (Revista quadrimestral de Ciência da Educação / Centro de estudos edução e sociedade - CEDES). Campinas, v. XXVI, a. XII, n. 75, 67-83, Agosto, 2001.

CORREAA, Paulo S. de A. O Estado e a formulação da política curricular: prescrições e inconfidências. 2000. Tese (Doutorado em Educação). Pontifícia Universidade Católica, São Paulo, 2000.

DEL PINO, Mauro. Políticas educacionais, emprego e exclusão social. In: FRIGOTTO, Gaudêncio, GENTILI, Pablo (Org.). A cidadania negada: políticas de exclusão na educação e no trabalho. São Paulo: Cortez; Buenos Aires, Argentina: Clacso, 2001.

DIAS SOBRINHO, José. Educação Superior: flexibilização e regulação ou avaliação e sentido público. In: DOURADO, L. F.; CATANI, Afrânio. M.; OLIVEIRA, João Francisco (org.). Políticas e gestão da educação superior - transformações recentes e debates atuais. São Paulo: Xamã, 2003, p. 97-135.

Quase-mercado, quase-educação, quase-qualidade. Raies - Avaliação/Revista da Rede de Avaliação Institucional da Educação Superior. Campinas: 2002, p. 9-33.

DOURADO, Luiz F.; OLIVEIRA, João F. Universidade pública: 
políticas e identidade institucional. Campinas: Autores Associados; Goiânia: Editora da UFG, 1999.

DRAIBE, Sonia M. As políticas sociais e o neoliberalismo - reflexões suscitadas pelas experiências latino-americanas. Revista da USP. São Paulo: Edusp, 1993.

FRIGOTTO,Gaudêncio. Apresentação. In: Educação e crise do trabalho: perspectiva de final de século. 6. ed. Petrópolis: Vozes, 2002. Coleção estudos culturais em educação.

GENTILI, Pablo. Educar para o desemprego: A desintegração da promessa integradora. In: FRIGOTTO, Gaudêncio (Org.). Educação e crise do trabalho: perspectiva de final de século. 6. ed. Petrópolis: Vozes, 2002. Coleção estudos culturais em educação.

GENTILI, Pablo. O currículo: uma reflexão sobre a prática. 3. ed. Porto Alegre: Artes Médicas, 1998.

GRAMSCI, Antonio. Maquiavel, a política e o Estado moderno. Rio de Janeiro: Civilização Brasileira, 1991.

MARQUES, Mara R. A. Autonomia ou flexibilização: o atual dilema do profissional docente. In: SGUISSARDI, Valdemar. (Org). Educação superior: velhos e novos desafios. São Paulo: Xamã, 2000a. p. 219-34.

MARQUES, Mara R.. Um fino tecido de muitos fios: mudança Social e Reforma Educacional em Minas Gerais. 2000. Tese (Doutorado em Educação). Universidade Metodista de Piracicaba, Piracicaba, 2000b.

NOGUEIRA, Marco Aurélio. Um Estado para a sociedade civil: temas éticos e políticos da gestão democrática. São Paulo: Cortez, 2004. 
OFFE, Claus. Problemas Estruturais do Estado Capitalista. Tradução de Bárbara Freitag. Rio de Janeiro: Tempo Brasileiro, 1984.

Sistema educacional, sistema ocupacional e política da educação - Contribuição à determinação das funções sociais do sistema educacional. Revista Educação e Sociedade (Revista quadrimestral de Ciência da Educação/Centro de Estudos Educação e Sociedade/CEDES). Campinas: CEDES, n. 35, p. 959, Abril, 1990.

PIMENTA, Carlos César. A reforma gerencial do Estado brasileiro no contexto das grandes tendências mundiais. In: RAP - Revista de Administração Pública, Rio de Janeiro: 32 (5), p. 173-99, set./ out. 1998.

POPKEWITZ, Tomas S. Reforma educacional: uma política sociológica - poder e conhecimento em educação. Tradução de Beatriz A. Neves. Porto Alegre: Artes Médicas, 1997.

SGUISSARDI, Valdemar; SILVA JÚNIOR, João dos R. Reconfiguração da educação superior e redefinição das esferas pública e privada no Brasil. 1997. Trabalho apresentado a XX Reunião Anual da Associação Nacional de Pós-graduação e Pesquisa em Educação (ANPED) (Sessão Especial - Reformas de educação superior na América Latina: autonomia e identidade), Caxambu, 1997.

SILVA, Sarita Medina. Diretrizes Curriculares Nacionais e a formação de professores: flexibilização e autonomia. 2006. Tese (Doutorado em Educação) - Universidade Estadual de Campinas, Campinas, 2006.

SILVA JÚNIOR, João dos R. Reforma da educação superior: a produção da ciência engajada ao mercado e de um novo pacto social. In: DOURADO, L. F.; CATANI, Afrânio. M.; OliveIrA, João

Educ. e Filos., Uberlândia, v. 21, n. 42, p. 193-226, jul./dez. 2007. 
Francisco (Org.). Políticas e gestão da educação superior transformações recentes e debates atuais. São Paulo: Xamã, 2003. p. 53-80.

Data de Registro 03/04/07

Data de Aceite 26/07/07 
